\title{
High-temperature Adhesion Promoter Based on (3-Glycidoxypropyl) Trimethoxysilane for Cu Paste
}

\author{
Jianwei Jiang, Yong Hwan Koo ${ }^{\dagger}$ Hye Won Kim, ${ }^{\dagger}$ Ji Hyun Park, ${ }^{\ddagger}$ Hyun Suk Kang, ${ }^{\dagger}$ \\ Byung Cheol Lee, ${ }^{\dagger, *}$ Sang-Ho Kim, ${ }^{*}$ Hee-eun Song, ${ }^{\S, *}$ and Longhai Piao* \\ Department of Chemistry, Kongju National University, Chungna 314-701, Korea \\ *E-mail: piaolh@kongju.ac.kr (L.P.); sangho1130@kongju.ac.kr (S.-H.K.) \\ ${ }^{\dagger}$ Radiation Integrated System Research Division, Korea Atomic Energy Research Institute (KAERI), Daejeon 305-353, Korea \\ *E-mail: bclee4@kaeri.re.kr \\ LLaser Plasma Engineering, University of Science and Technology (UST), Daejeon 305-350, Korea \\ § Photovoltaic Laboratory, Korea Institute of Energy Research, Daejeon 305-343, Korea. *E-mail: hsong@kier.re.kr \\ Received May 27, 2014, Accepted June 20, 2014
}

\begin{abstract}
To realize copper-based electrode materials for printed electronics applications, it is necessary to improve the adhesion strength between conductive lines and the substrate. Here, we report the preparation of $\mathrm{Cu}$ pastes using (3-glycidoxypropyl) trimethoxysilane (GPTMS) prepolymer as an adhesion promoter (AP). The $\mathrm{Cu}$ pastes were screen-printed on glass and polyimide (PI) substrates and sintered at high temperatures $\left(>250{ }^{\circ} \mathrm{C}\right)$ under a formic acid/ $\mathrm{N}_{2}$ environment. According to the adhesion strengths and electrical conductivities of the sintered $\mathrm{Cu}$ films, the optimized $\mathrm{Cu}$ paste was composed of $1.0 \mathrm{wt} \%$ GPTMS prepolymer, $83.6 \mathrm{wt} \% \mathrm{Cu}$ powder and $15.4 \mathrm{wt} \%$ vehicle. After sintering at $400{ }^{\circ} \mathrm{C}$ on a glass substrate and $275{ }^{\circ} \mathrm{C}$ on a PI substrate, the $\mathrm{Cu}$ films showed the sheet resistances of $10.0 \mathrm{~m} \Omega / \mathrm{sq}$. and $5.2 \mathrm{~m} \Omega / \mathrm{sq}$., respectively. Furthermore, the sintered $\mathrm{Cu}$ films exhibit excellent adhesion properties according to the results of the ASTM-D3359 standard test.
\end{abstract}

Key Words : Printed electronics, High-temperature adhesion promoter, Cu paste, (3-Glycidoxypropyl) trimethoxysilane

\section{Introduction}

Printed electronics, because of their lower cost, lower contribution to pollution and fewer process steps compared with electronics developed by the conventional lithography and etching process, have been employed in a variety of applications such as solar cells, ${ }^{1}$ radio-frequency identification $\operatorname{tags}^{2}$ and other flexible electronics. ${ }^{3}$ Printed electronics processes provide direct-written patterns on substrates using any solution-based material, including metal particles, ${ }^{4}$ semiconductor material, ${ }^{5}$ conducting polymers, ${ }^{6}$ carbon nanotubes ${ }^{7}$ and graphenes. ${ }^{8}$

Silver particles represent one of the most commonly used conducting materials due to the particles' high electrical conductivity and chemical stability. ${ }^{9}$ However, the high cost of silver-based conducting materials limits their wide industrial application. Therefore, it is important to develop a less expensive printable conducting material. One of the most promising alternatives is $\mathrm{Cu}$ due to its high electrical conductivity, low cost and reduced electromigration effect. ${ }^{10}$ However, bulk $\mathrm{Cu}$ (Tm: $1083{ }^{\circ} \mathrm{C}$ ) has a higher melting temperature than bulk $\mathrm{Ag}\left(\mathrm{Tm}: 962{ }^{\circ} \mathrm{C}\right.$ ); thus, the electrical conductivity of $\mathrm{Cu}$ films increases with increasing sintering temperature. For example, Jeong reported that the resistivity of a $\mathrm{Cu}$ conductive film decreased from $100 \Omega \mathrm{cm}$ to $10^{-4}$ $\Omega \mathrm{cm}$ as the sintering temperature increased from $200{ }^{\circ} \mathrm{C}$ to $325{ }^{\circ} \mathrm{C} .{ }^{11}$ In addition, $\mathrm{Cu}$ particles are easily oxidized to form a surface oxide layer, which reduces their electrical conductivity. To address the oxidation problem, harsh sintering conditions such as high temperature and a reduction environment composed of, for example, hydrogen, ${ }^{12}$ carboxylic acid $^{13}$ or formic acid/alcohol ${ }^{14}$ should be employed. However, the adhesion strength between the conducting film and the substrate is deteriorated under these harsh conditions, especially, when an organic primer is used as the adhesion promoter (AP). Therefore, there is a critical need for an appropriate AP for $\mathrm{Cu}$ paste.

Previously, we demonstrated that GPTMS prepolymer AP showed excellent adhesion between Ag nano-ink and glass/ polyethylene terephthalate (PET) substrates due to its characteristic organic/inorganic functional groups. ${ }^{15}$ Considering that the inorganic polymer, due to its alkoxysilane groups, is stable up to $400{ }^{\circ} \mathrm{C}$ and the polymer exhibits chemical stability due to the sturdy $\mathrm{Si}-\mathrm{O}$ bonds along its backbone, ${ }^{16}$ GPTMS prepolymer might be used as an effective hightemperature AP for $\mathrm{Cu}$ paste. Herein, we report that GPTMS prepolymer AP for $\mathrm{Cu}$ paste is suitable for high- temperature sintering $\left(>250{ }^{\circ} \mathrm{C}\right)$.

\section{Experimental}

Materials and Methods. $\mathrm{Cu}$ powders with a particle size of 1-2 $\mu \mathrm{m}$ were obtained from Green Resource Co. Ltd, Korea. GPTMS ( $\geq 98 \%$ ), 2-(2-butoxyethoxy)ethyl acetate ( $\geq 99.2 \%$ ), diethylene glycol monobutyl ether $(\geq 99.0 \%)$, tetrahydrofuran $(\geq 99.0 \%)$, formic acid $(\geq 95 \%)$ and hydro- 
chloric acid solution $(\mathrm{HCl}, 0.1 \mathrm{M})$ were purchased from Sigma-Aldrich. Ethyl cellulose MED-70 (viscosity range 63-77 mPa.s) was supplied by Dow Chemical Co. The resultant sintered films and the interface between the PI substrates and $\mathrm{Cu}$ films were characterized by scanning electron microscopy (SEM, SNE 4000M). The sintered films was characterized by X-ray diffraction (XRD) using a diffractometer (DMAX-2000 $(18 \mathrm{~kW}))$ with $\mathrm{Cu} \mathrm{K \alpha}$ radiation $(\lambda=0.154 \mathrm{~nm})$. The sheet resistance of the $\mathrm{Cu}$ films was measured using a SR-4-6 four-point probe (Modu systems, Korea). The adhesion strength between the $\mathrm{Cu}$ films and the substrates (glass or PI) was measured according to the corresponding American Standard Test Method (ASTMD3359). Adhesion test of the film was performed with scotch tape after a cross hatch cutter scratch. The adhesion strength was rated according to a scale ranging from $0 \mathrm{~B}$ (weakest) to 5B (strongest).

Synthesis of the Adhesion Promoter GPTMS prepolymer was synthesized by a modified method. ${ }^{17}$ Briefly, GPTMS (23.6 g) and distilled water $(5 \mathrm{~mL})$ were dissolved in THF $(100 \mathrm{~mL})$, and $0.1 \mathrm{M} \mathrm{HCl}(5 \mathrm{~mL})$ was added as a catalyst. The resulting solution was heated to $90^{\circ} \mathrm{C}$ and refluxed for $72 \mathrm{~h}$. After the reaction, the cooled mixture solution was diluted with ethyl acetate $(300 \mathrm{~mL})$ and washed with distilled water $(50 \mathrm{~mL})$ three times. The organic solution was dried over anhydrous $\mathrm{MgSO}_{4}$, filtered and concentrated to yield a colorless viscous liquid (18.2 g).

Preparation of $\mathrm{Cu}$ Paste The vehicle was obtained by mixing ethyl cellulose MED-70 (7.0 wt \%), 2-(2-butoxyethoxy) ethyl acetate (83.7 wt \%) and diethylene glycol monobutyl ether $(9.3 \mathrm{wt} \%)$ in a glass beaker and mechanically mixing for $8 \mathrm{~h}$ at $75^{\circ} \mathrm{C}$. Cu pastes were prepared by mixing the $\mathrm{Cu}$ powders $(83.6 \mathrm{wt} \%)$ with the vehicle and GPTMS prepolymer, grinding the mixtures and submitting them to a three-roll mill process.

Screen-printing and Sintering Conditions The formulated pastes were screen-printed (type GP-600FV, Dae Young Tech, Korea) through a nylon mesh on a $10 \times 10 \mathrm{~cm}^{2}$ glass or PI substrate at a squeegee speed of $100 \mathrm{~mm} / \mathrm{s}$ and offcontact distance of $3 \mathrm{~mm}$. The screen-printed samples were then sintered in a glove box on a hotplate under a $\mathrm{N}_{2}$ $(99.99 \%) /$ saturated formic acid environment for $10 \mathrm{~min}$.

\section{Results and Discussion}

Conductive $\mathrm{Cu}$ films were prepared by paste formulation, screen-printing and sintering. The adhesion strengths and sheet resistances of the films are shown in Figure 1(a). The GPTMS prepolymer content was observed to affect not only the adhesion strength but also the electrical properties of the conducting films. The adhesion strength increased with GPTMS prepolymer content. Without GPTMS prepolymer, the $\mathrm{Cu}$ films were easily stripped from glass substrate after sintering at $400{ }^{\circ} \mathrm{C}$ (Figure 1(b)) and also easily removed from the PI substrate by the tape test after sintering at 300 ${ }^{\circ} \mathrm{C}$; thus, the films were categorized as class $0 \mathrm{~B}$ films. For the $\mathrm{Cu}$ film containing $0.5 \mathrm{wt} \%$ GPTMS prepolymer, $90 \%$
(Figure 1(c)) and $75 \%$ of the films on the glass and PI substrates remained after the tape test and were categorized as class $3 \mathrm{~B}$ and $2 \mathrm{~B}$ films, respectively. As the content of GPTMS prepolymer reached $1.0 \mathrm{wt} \%$, nearly $100 \%$ (Figure $1(\mathrm{~d})$ ) of the film remained on both substrates, indicating excellent adhesion strength (class 5B). The adhesion strength of the film containing $2.0 \mathrm{wt} \%$ GPTMS prepolymer was similar to that containing $1.0 \mathrm{wt} \%$ GPTMS prepolymer. However, the sheet resistance tended to increase with the GPTMS prepolymer content. The sheet resistance of the $\mathrm{Cu}$ films increased from $1.6 \mathrm{~m} \Omega / \mathrm{sq}$. to $10.0 \mathrm{~m} \Omega / \mathrm{sq}$. for the glass substrate and from $3.3 \mathrm{~m} \Omega / \mathrm{sq}$. to $43.4 \mathrm{~m} \Omega / \mathrm{sq}$. for the PI substrate as the GPTMS prepolymer content increased from 0 to $2.0 \mathrm{wt} \%$. The optimum content of GPTMS prepolymer was $1.0 \mathrm{wt} \%$ for both substrates.

To optimize the electrical conductivity, $\mathrm{Cu}$ films containing $1.0 \mathrm{wt} \%$ GPTMS prepolymer were sintered at different temperatures on glass and PI substrates. As shown in Figure 1(e), for the films deposited on the glass substrate, the sheet resistance decreased from $50.2 \mathrm{~m} \Omega / \mathrm{sq}$. to $10.0 \mathrm{~m} \Omega / \mathrm{sq}$. as the sintering temperature increased from $275{ }^{\circ} \mathrm{C}$ to $400{ }^{\circ} \mathrm{C}$, and the distribution of the sheet resistance became narrower. This result can be rationalized by considering that more organic vehicle in the $\mathrm{Cu}$ film is removed as the sintering temperature increases. More importantly, for the $\mathrm{Cu}$ film containing $1.0 \mathrm{wt} \%$ GPTMS prepolymer, the excellent adhesion strength $(5 \mathrm{~B})$ on the glass substrate could be preserved at high temperatures, even after sintering at $400{ }^{\circ} \mathrm{C}$ (Figure 1(f)). For the $\mathrm{Cu}$ films deposited on the PI substrate, the film containing $1.0 \mathrm{wt} \%$ GPTMS prepolymer also exhibited good adhesion strength (5B); however, as the sintering temperature increased from $275{ }^{\circ} \mathrm{C}$ to $300{ }^{\circ} \mathrm{C}$, the sheet resistance increased from $5.2 \mathrm{~m} \Omega / \mathrm{sq}$. to $11.7 \mathrm{~m} \Omega / \mathrm{sq}$. (Figure 1(e)). Moreover, the sheet resistance increased dramatically to $42.5 \mathrm{~m} \Omega / \mathrm{sq}$. when the sintering temperature reached 325 ${ }^{\circ} \mathrm{C}$, and the adhesion strength decreased to $3 \mathrm{~B}$. For the $\mathrm{Cu}$ films containing $0 \mathrm{wt} \%, 0.5 \mathrm{wt} \%$ or $2.0 \mathrm{wt} \%$ GPTMS prepolymer, the sheet resistance was also observed to increase dramatically, and the adhesion strength decreased at $325^{\circ} \mathrm{C}$ (data not shown). These results can be attributed to the fact that as the glass transition temperature of PI is exceeded, the plasticized PI substrate reduces the adhesion strength rather than deteriorating the GPTMS prepolymer at $325^{\circ} \mathrm{C}$. Interestingly, the adhesion strength of the film without GPTMS prepolymer was $2 \mathrm{~B}$ after sintering at $275^{\circ} \mathrm{C}$, which can be explained by considering the effects of the remaining vehicle. However, as the sintering temperature increased to $300{ }^{\circ} \mathrm{C}$, the adhesion strength decreased to $\mathrm{OB}$. By comparison, the adhesion strength (5B) of the $\mathrm{Cu}$ film containing $1.0 \mathrm{wt} \%$ GPTMS prepolymer and sintered at $300{ }^{\circ} \mathrm{C}$ demonstrates that the GPTMS prepolymer is stable at $300^{\circ} \mathrm{C}$. Based on these results, it is concluded that the GPTMS prepolymer AP plays a vital role in preserving the adhesion of $\mathrm{Cu}$ films at high sintering temperature, even at $400{ }^{\circ} \mathrm{C}$.

The optimum results are a sheet resistance of $5.2 \mathrm{~m} \Omega / \mathrm{sq}$. after sintering at $275^{\circ} \mathrm{C}$ for the PI substrate and a sheet resistance of $10.0 \mathrm{~m} \Omega / \mathrm{sq}$. after sintering at $400{ }^{\circ} \mathrm{C}$ for the 

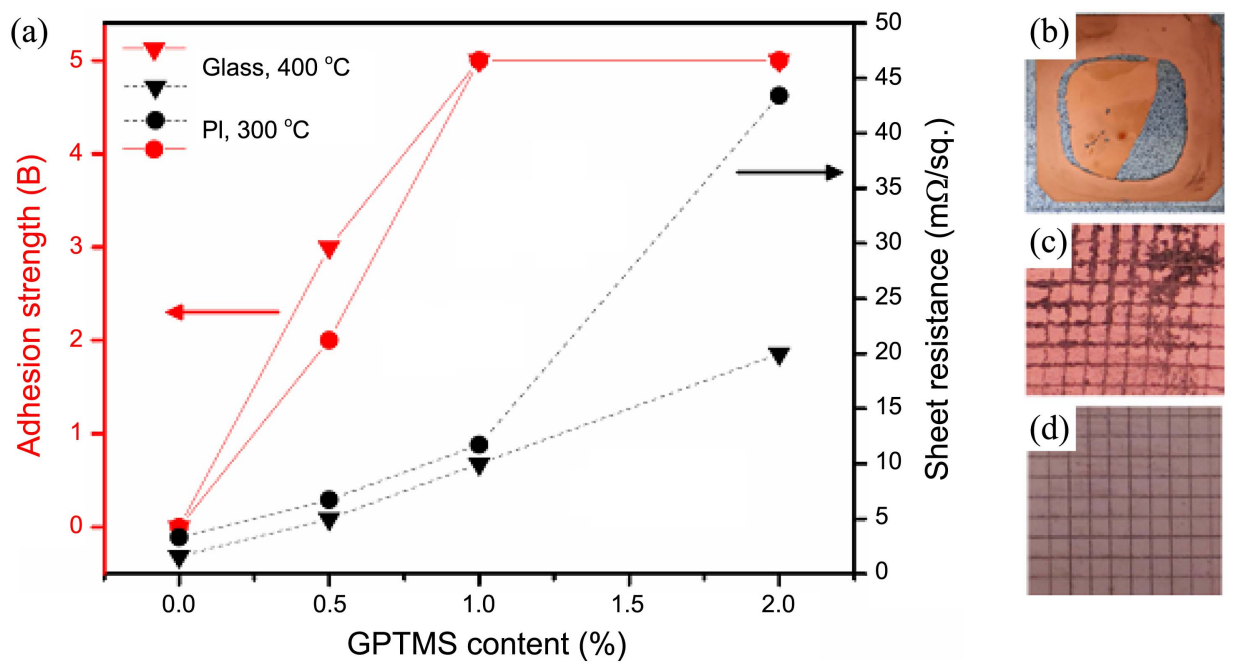

(d)
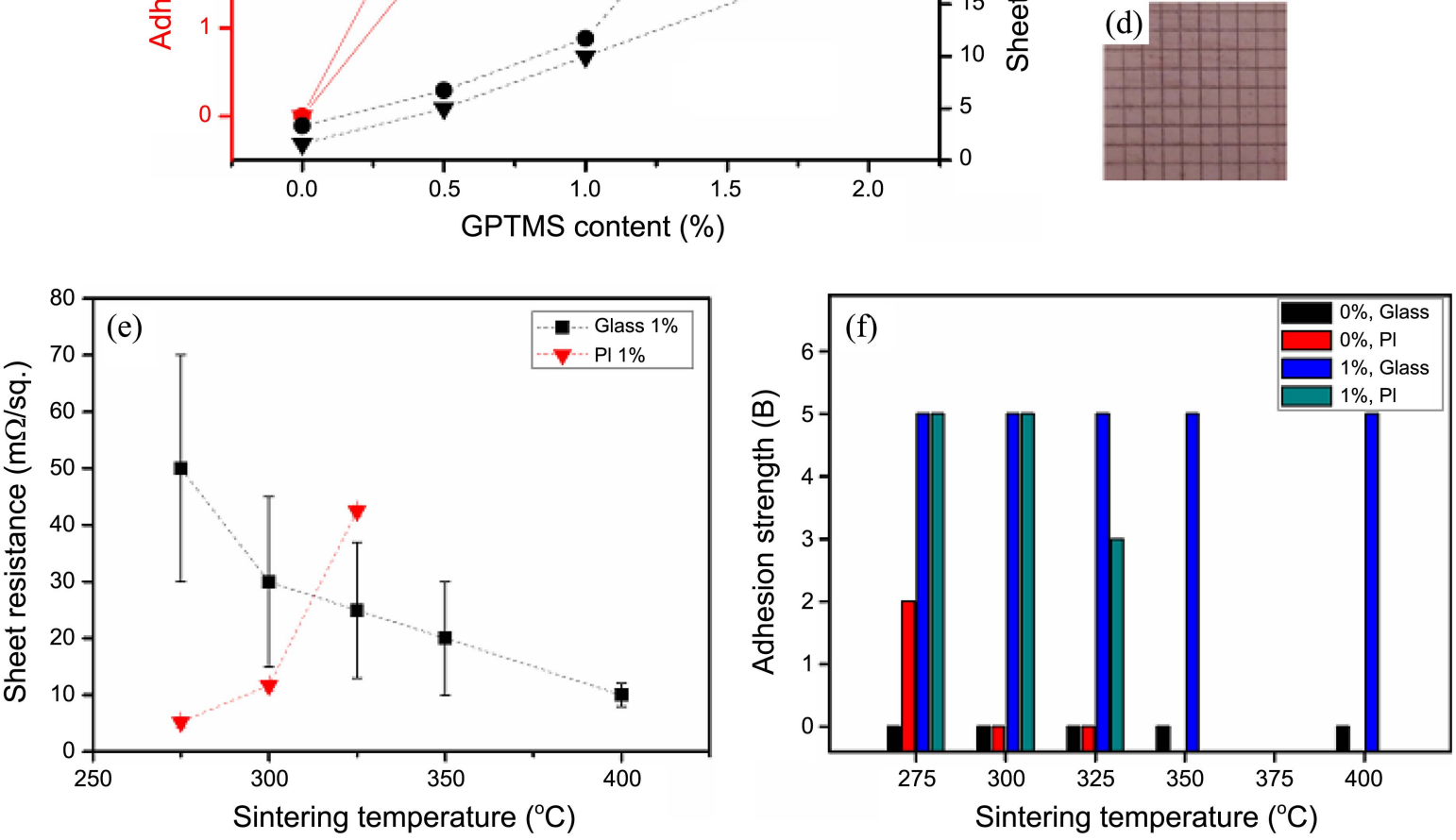

Figure 1. (a) Sheet resistance and adhesion strength as a function of GPTMS prepolymer content. Digital camera image of test results for the Cu films: (b) $0 \mathrm{wt} \%$, (c) $0.5 \mathrm{wt} \%$ and (d) $1.0 \mathrm{wt} \%$ GPTMS prepolymer on glass substrates. (e) The sheet resistance as a function of sintering temperature on PI/glass substrates. (f) The ASTM-D3359 test results.

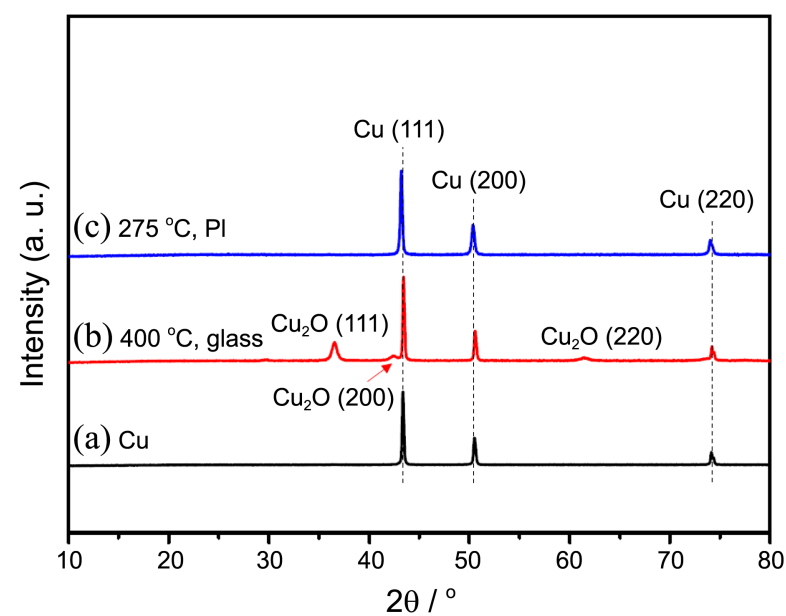

Figure 2. XRD patterns: (a) $\mathrm{Cu}$ powders, (b) $\mathrm{Cu}$ film sintered at $400{ }^{\circ} \mathrm{C}$ on glass substrate and (c) $\mathrm{Cu}$ film sintered at $275^{\circ} \mathrm{C}$ on PI substrate.

glass substrate.

$\mathrm{XRD}$ was used to characterize the sintered $\mathrm{Cu}$ films prepared under the optimum conditions. The XRD pattern of the $\mathrm{Cu}$ powder (Figure 2(a)) shows three distinct diffraction peaks at $43.3^{\circ}, 50.5^{\circ}$ and $74.2^{\circ}$, corresponding to the three intense peaks of $\mathrm{Cu}$ (JCPDS 65-9026). However, the peak at $36.5^{\circ}$, which can be indexed as (111) diffraction of $\mathrm{Cu}_{2} \mathrm{O}$ (JCPDS 01-1142), was observed after sintering the films deposited on the glass substrate at $400{ }^{\circ} \mathrm{C}$, indicating the partial oxidation of the $\mathrm{Cu}$ powder (Figure 2(b)). Fortunately, no measurable peak at $36.5^{\circ}$ was observed in the XRD pattern for the films deposited on the PI substrate and sintered at $275^{\circ} \mathrm{C}$ (Figure 2(c)), indicating a high level of phase purity. The difference in the XRD patterns for the two types of $\mathrm{Cu}$ films can be attributed to the rate of oxidation being faster than the rate of reduction at high temperature. The presence of $\mathrm{Cu}_{2} \mathrm{O}$ would result in a higher sheet resistance for the glass substrate $(10.0 \mathrm{~m} \Omega / \mathrm{sq}$.) than that for the PI substrate $(5.2 \mathrm{~m} \Omega / \mathrm{sq}$.) under the optimum conditions.

The role of the GPTMS prepolymer AP was studied by detecting the interfaces between the PI substrate and $\mathrm{Cu}$ films using cross-sectional SEM images (Figure 3). Figure 3(a) shows very poor adhesion between the $\mathrm{Cu}$ powder and PI substrate at the interface of the two layers without any adhesion promoter. However, in Figure 3(b), for the film 

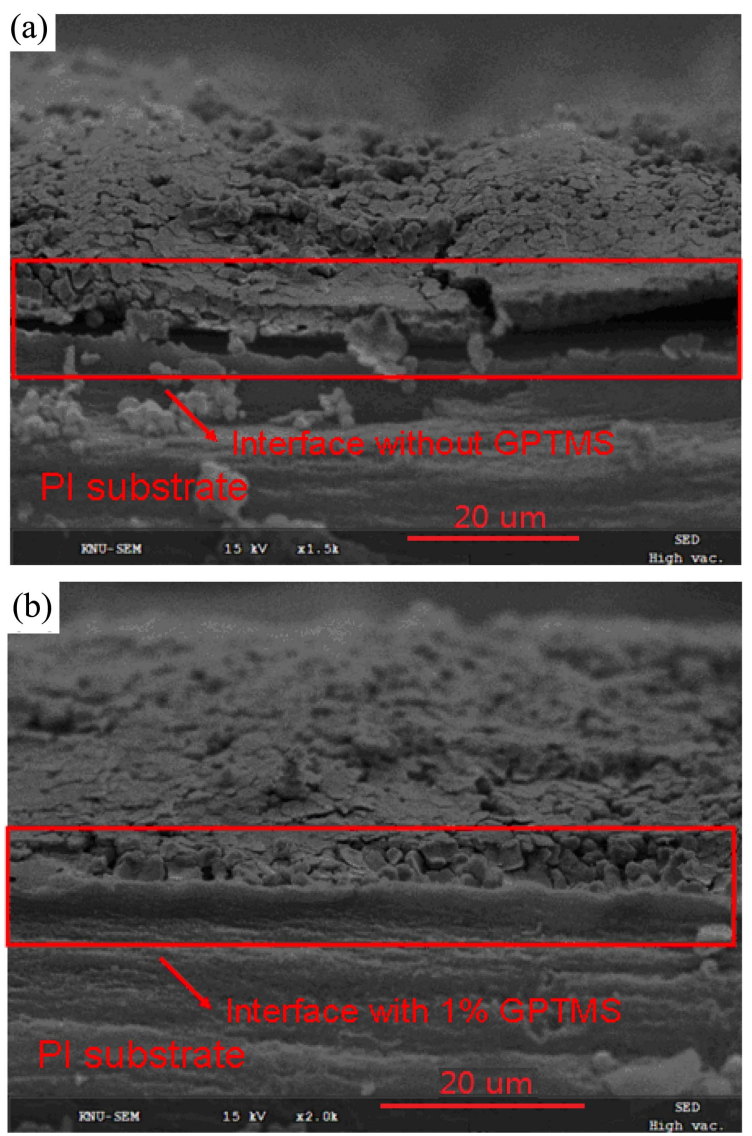

Figure 3. (a) Cross-sectional image of film without GPTMS prepolymer and (b) film with $1.0 \mathrm{wt} \%$ GPTMS prepolymer on PI substrate sintered at $275^{\circ} \mathrm{C}$ in $\mathrm{N}_{2} / \mathrm{HCOOH}$ environment.
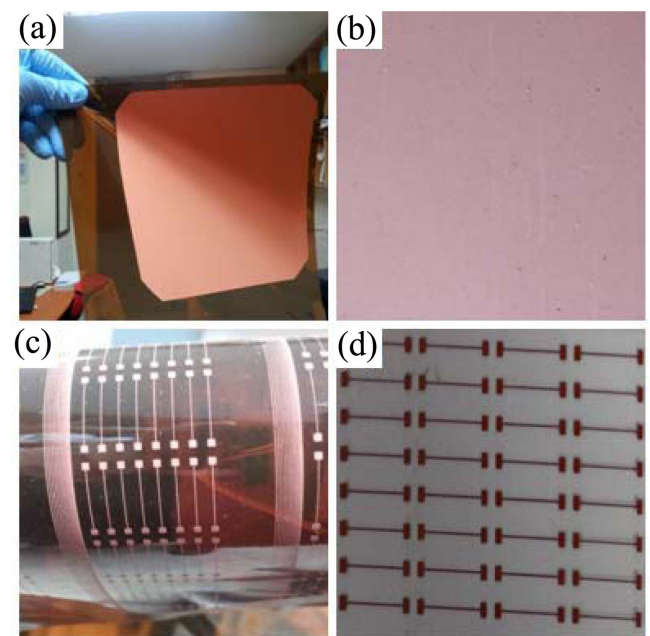

Figure 4. Screen-printed patterns: (a) and (c) on a PI substrate; (b) and (d) on a glass substrate.

containing $1.0 \mathrm{wt} \%$ GPTMS prepolymer, a dense layer can be observed without any exfoliation at the interface. The two images confirm that GPTMS prepolymer facilitates the adhesion of the $\mathrm{Cu}$ layer to the PI substrate.

To evaluate the applicability of the prepared $\mathrm{Cu}$ paste containing GPTMS prepolymer in producing printed electronics, conducting patterns were constructed on glass and
PI substrates by screen-printing. Figure 4(a) and 4(b) show the $\mathrm{Cu}$ films deposited on PI and glass substrates, and Figure 4(c) and 4(d) show the conductive $\mathrm{Cu}$ lines. The formation of a uniform $\mathrm{Cu}$ surface on the substrates indicates that $\mathrm{Cu}$ powders were closely packed in the designed pattern. When the PI substrate was bent, the conductive line remained on the substrate without detachment. The $\mathrm{Cu}$ paste containing GPTMS prepolymer exhibited good adhesion on both the glass and PI substrates.

\section{Conclusion}

In summary, GPTMS prepolymer, as an adhesion promoter, exhibits excellent adhesion to glass and PI substrates. In addition, the good adhesion strength of the prepolymer is preserved after sintering at high temperature, i.e., at $400{ }^{\circ} \mathrm{C}$ for the glass substrate and $300{ }^{\circ} \mathrm{C}$ for the PI substrate. By optimizing the experimental conditions, the deposited $\mathrm{Cu}$ films showed low sheet resistances of $10.0 \mathrm{~m} / \mathrm{sq}$. and 5.2 $\mathrm{m} \Omega /$ sq., respectively, after sintering at $400{ }^{\circ} \mathrm{C}$ on glass substrates and $275^{\circ} \mathrm{C}$ on PI substrates. It is believed that the high-temperature AP based on GPTMS prepolymer can be used in the manufacture of printed electronics, where high sintering temperatures are necessary.

Acknowledgments. This work was conducted under the framework of Research and Development Program of the Korea Institute of Energy Research (KIER) (B4-2422).

\section{References}

1. Ionkin, A. S.; Fish, B. M.; Li, Z. R.; Lewittes, M.; Soper, P. D.; Pepin, J. G.; Carroll, A. F. ACS Appl. Mater. Interf. 2011, 3, 606.

2. Subramanian, V.; Frechet, J. M. J.; Chang, P. C.; Huang, D. C.; Lee, J. B.; Molesa, S. E.; Murphy, A. R.; Redinger, D. R.; Volkman, S. K. Proceedings of the IEEE 2005, 93, 1330.

3. Ahn, B. Y.; Duoss, E. B.; Motala, M. J.; Guo, X.; Park, S.-I.; Xiong, Y.; Yoon, J.; Nuzzo, R. G.; Rogers, J. A.; Lewis, J. A. Science 2009, 323, 1590.

4. Perelaer, J.; Smith, P. J.; Mager, D.; Soltman, D.; Volkman, S. K.; Subramanian, V.; Korvink, J. G.; Schubert, U. S. J. Mater. Chem. 2010, 20, 8446 .

5. Mei, J.; Diao, Y.; Appleton, A. L.; Fang, L.; Bao, Z. J. Am. Chem. Soc. 2013, 135, 6724 .

6. Yoo, J. E.; Lee, K. S.; Garcia, A.; Tarver, J.; Gomez, E. D.; Baldwin, K.; Sun, Y.; Meng, H.; Nguyen, T.-Q.; Loo, Y.-L. PNAS 2010, 107, 5712 .

7. De Volder, M. F. L.; Tawfick, S. H.; Baughman, R. H.; Hart, A. J. Science 2013, 339, 535.

8. Karuwan, C.; Wisitsoraat, A.; Phokharatkul, D.; Sriprachuabwong, C.; Lomas, T.; Nacapricha, D.; Tuantranont, A. RSC Advances 2013, 3, 25792.

9. Chen, S.-P.; Kao, Z.-K.; Lin, J.-L.; Liao, Y.-C. ACS Appl. Mater. Interf. 2012, 4, 7064.

10. Deng, D.; Cheng, Y.; Jin, Y.; Qi, T.; Xiao, F. J. Mater. Chem. 2012, $22,23989$.

11. Jeong, S.; Woo, K.; Kim, D.; Lim, S.; Kim, J. S.; Shin, H.; Xia, Y.; Moon, J. Adv. Funct. Mater. 2008, 18, 679.

12. Kim, Y.; Lee, B.; Yang, S.; Byun, I.; Jeong, I.; Cho, S. M. Curr. Appl. Phys. 2012, 12, 473.

13. Woo, K.; Kim, Y.; Lee, B.; Kim, J.; Moon, J. ACS Appl. Mater. Interf. 2011, 3, 2377. 
14. Kim, I.; Kim, J. J. Appl. Phys. 2010, 108.

15. Hong, J. U.; Kumar, A. B. V.; Han, H. S.; Koo, Y. H.; Kim, H. W.; Park, J. H.; Kang, H. S.; Lee, B. C.; Piao, L. H.; Kim, S. H. Bull. Korean Chem. Soc. 2013, 34, 2569.
16. Chenoweth, K.; Cheung, S.; van Duin, A. C. T.; Goddard, W. A.; Kober, E. M. J. Am. Chem. Soc. 2005, 127, 7192.

17. Shajesh, P.; Smitha, S.; Aravind, P. R.; Warrier, K. G. K. J. Colloid Interface Sci. 2009, 336, 691. 